\begin{tabular}{ccc}
\hline & International Journal of Engineering \& Technology, $7(4.38)(2018) 1270-1274$ \\
SPC & International Journal of Engineering \& Technology \\
\hline
\end{tabular}

\title{
Residents' Health Awareness of the Sustainability of Indoor Air Quality in High Rise Building
}

\author{
123School of Environmental Science \\ University of Indonesia \\ Jakarta, Indonesia \\ nurwidyaningrum@yahoo.com \\ 4Department of Environmental Health \\ Faculty of Public Health, University of Indonesia \\ Depok, Indonesia \\ *Corresponding author E-mail: haryoto_k@yahoo.com
}

Dyah Nurwidyaningrum1, Setyo S. Moersidik2, Emirhadi Suganda3 and Haryoto Kusnoputranto4

\begin{abstract}
This study was concerned with the residents' health awareness of their behavior which affected indoor air quality (IAQ) in high rise building in Jakarta, Indonesia. This analysis was aimed to describe the difference between the strength of the influence of residents' dimension to IAQ in unit with knowledge variable and that of without knowledge variable. The behavior based on health knowledge became the parameter of health awareness. The descriptive result indicated that the residents in Rusunami high rise building were welleducated people but not all of them had good behavior. Participants whose occupations are related to health tended to take care of indoor air quality better than those from other occupation. With the structural equation modeling (SEM), the construct of residents' dimension was formulated based on physical and psychological comfort, as well as involving the healthy life participation and pollution activities. It was found that this combination drove behavioral change to IAQ in high rise building. Partial Least Square analysis showed that the knowledge of IAQ could raise the effect of residents' dimension to IAQ in unit from $15.2 \%$ to $16.6 \%$.
\end{abstract}

Keywords: health awareness; High Rise Building; Indoor Air Quality; Residents' Dimension; Residents' Knowledge

\section{Introduction}

Previous studies revealed that formal program for the residents and the knowledge of residents habit were predicted to be able to improve human's health for minimizing the consumption of natural resources and correcting the indoor comfort [1-3]. Unfortunately, such studies indicated that behavioral change through increasing the resident knowledge did not always obtain the expected output. In reality, without some high supplementary cost and effort, the residents' awareness is unadequate [4]. In case of the exposure behaviors, the resident knowledge are closely related to the daily activities [5-6]. Initial investigations provided that the residents with indoor air quality (IAQ) health awareness were still polluting the unit, such as by smoking, eating disturbing odor food, and using chemical fragrance. According to Maslow theory of human motivation [7], without the manager completing resident basic need, the residents' health awareness can not be the drive for IAQ sustainability in high rise building [8]. Thus, a study emphasizing on the fulfillment of the residents' basic needs: physical and psychological comfort which influences IAQ besides the residents' participation and pollution activities is important. High rise housing increases rapidly in urban area of developing countries, so does in Jakarta. With the population growth rate of $1,09 \%$ on Central Bureau of Statistics in 2016, people in urban area are encouraged to live in a high rise building. The important thing to concern relating to the encouragement is that the health risk in indoor is 2-5 times higher than that of outdoor [9]. Due to indoor air pollution, the respiratory disease and mortality are amongst the greatest environmental threats to health in the developing countries of Asia [10]. In developing countries, the recent quantity of affordable and effective interventions for reducing the risks related with exposure to indoor smoke from household energy technology is restricted [11]. In Jakarta, $\mathrm{PM}_{10}$ [12] and tobacco [13] are revealed as the pollutants that affect residents' health in the household as well as the apartment. Thus, in high rise residential building, IAQ issues are very important because air pollution from inside or outside the building is more quickly spread to other units than that of in the horizontal housing. According to the sustainability theory in order to achieve effective IAQ in high rise building, the management needs to carry out the balance of three aspects: environmental, social, and economic [9]. On the social aspect, many studies have revealed the behavioral change through the resident perceptions of IAQ, the impact, and the type activities that cause indoor pollution but only few that have investigated the influence of residents' knowledge on IAQ. In the residential management, humans through behavioral change hold a major role in keeping the healthy indoor [14-15] which also give impact on the environmental, economic aspects, and the unity of the sustainability of their lives [16].

The residents' awareness through the health knowledge can be one of the drives in the sustainability of IAQ because it encourages behavioral change. It was hypothesized that if the participants had received training for high performance building features, they would be more satisfied with their environment than those who 
had not [2]. Maslow has said that most basic need of people is physical survival, and it will be the first thing that encourages their behavior. They are driven to ensure needs and that some needs take precedence over and when once that level is fulfilled the next level up is what drives them [8]. In addition, Hawkes has stated that humans feel the value of self-existence which is necessary to make the meaning of life [17]. In residential buiding of developing countries, the formation of health educational programs is crucial and the programs should first address attitudes because the knowledge of adverse health symptoms has an influence on actions taken to reduce household exposures. These actions seems to be more influenced by cultural practices from one generation to another [18].

Therefore this study focused on the residents' health awareness through IAQ knowledge as the drive variable between resident dimension and IAQ in unit of resident. The purpose of this study was to identify the influence of the residents' IAQ knowledge on residents' dimension and IAQ in unit. This study compared the differences of the influence of resident dimension to IAQ in unit with and without knowledge. The novelty of this research was that the residents' IAQ knowledge became the intellectual capital that could encourage good social behavior for the residents to participate in optimizing the IAQ through carefully avoiding the acts that might lead to pollutants, with the provision of the manager who sincerely strove to meet physical and psychological comfort requirements through some expected communication. The residents with health awareness could participate in optimizing IAQ in high rise building if they felt their human dimensions need to be satisfied well so that they were easily encouraged to do good deeds to others.

\section{2. material and methods}

The data were taken on the apartment located in central Jakarta. It is 2.9 ha and $80 \%$ of land are facilities, circulations space, and parks. When this study started, $50 \%$ of the building facilities were completed. High rise housing in Jakarta is divided into two types: (a) the housing (rusunawa) with leasing system to local government who provided the subsidy for its development and (b) the apartment owned by the private company which is intended for the middle to high income society. This study was conducted on the type of the apartment called rusunami owned by the private company. This apartment has been just inhabited for 5 years and the manager is a new company engaged in the management of high rise housing.

The participants were those who were staying in two tower apartments from the construction phase one. The residents' requirements in this study were people who had lived for more than a year in the unit and were above the age of sixteen. The participants were determined purposively to represent the distribution of floors of the building level. Each unit was represented by a participant. One unit was inhabited by a family consisting of 1 to 4 people but mostly consisting of only 2 people. The unit is $33 \mathrm{~m}^{2}$ and consists of 2 bedrooms, 1 living room, and 1 bathroom. The total number of participants were 42 . The data collecting was conducted from June to August 2017. It was the dry season with IAQ condition at the limit of comfort, and maximum temperature. This study used quantitative method. The Likert scale (1-5) was used for grouping the residents' responses. The data collecting was conducted in two ways, using questionnaires for collecting data related to the residents and using measurement with IAQ meter for collecting data related IAQ in units. The data analysis used partial least square (PLS) with program SmartPLS 3.2. Presentation of SmartPLS analysis used comparative method. A descriptive way was applied to illustrate the residents characteristics.

Independent variables were the residents' dimension and IAQ knowledge, while the dependent variable was IAQ in unit. The residents' dimension consisted of four indicators: psychological condition, physical comfort, participation, and polluting activities. The psychological condition and physical comfort were as the residents' basic need variables, while the participation and polluting activities were as dimensional influence of occupants of the IAQ. The IAQ knowledge had two indicators: hygiene and pollutant impact. IAQ in unit was formed from four indicators: $\mathrm{CO}, \mathrm{CO}_{2}$, humidity, and temperature. Interval values determination of IAQ in unit, used PERMENKES number 1077.

\section{Result and disscussion}

Most of the participants come from Jakarta who choose to live close to their workplace and their activity. They tend to choose the practicality of life with supporting facilities in the apartment, such as food court, laundry, cleaning services, and online transportation. The age interval was between 18-56 years old but participants are mostly young employees aged $18-37$ years old. They have a fairly good education and employees with various occupations. Focusing on the discussion of health awareness and participation of the IAQ, the participants were grouped based on the background of their work on health training and IAQ.

Figure 1(a) shows that there are 38\% participants whose occupations are related to IAQ: health and construction occupations. Participants whose occupations in the health area are $9 \%$ and those in the construction are $27 \%$. The rest of $64 \%$ have no work related to IAQ knowledge. Occupation can contribute to health care engagement [19], so there are potential residents who can build the quality of health in the building.

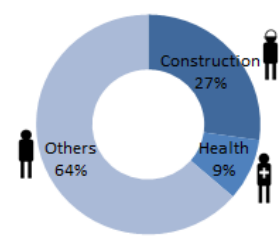

(a)

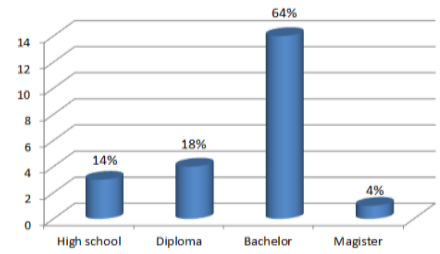

(b)
Fig 1. A chart of work fields and level education of participants.

Figure 1(b) reveals that most participants have a fairly good level of education. Out of all residents $64 \%$ of them graduated from bachelor level, $18 \%$ graduated from diploma, and $4 \%$ graduated from magister. Only $14 \%$ of the participants graduated from high school. Most participants are well-educated and generally receive sufficient income. According to the effects of age on intensity and priority of life needs [20], with their education, they need physiological, safety, sense of belonging, and love, looking at their young and productive age. In Indonesia, diploma and bachelor graduates are categorized as level 4-6 and able to work as executors and analysts who have the critical power to solve the problem according to PERMENDIKTI number 44 . Thus, they would be critical people but easily encouraged to achieve healthy life. In the next discussion, on the PLS analysis, the level of education does not become part of the moderator variable because in this study the education level of participant is good, so it does not have a significant influence in the PLS analysis.

Generally, the unit conditions are clean and the unit sizes really fit. The Units have already been equipped with compact furniture. The finishing surface of the wall is very good and covered with wall paper. The rooms of each unit are not big but perfect for resting. Window frames and doors are made of polyvinyl-chloride material, making them easy to be cleaned. There are two types of air conditioning used in typical unit: air conditioner (AC) and exhaust fan. AC is located in master bedroom and living room, on the facade wall, whereas the exhaust fan is placed in the bathroom on the wall of the building facade and in the bedroom on the wall between the master bedroom and the second bedroom. With such system, air can flow to all parts of the room, so the residents feel comfortable, even if the AC is turned off occasionally. 
Residents' knowledge, in this study, was divided into two parts: knowledge about pollution sources and understanding on IAQ. Knowledge about pollution sources was the residents' knowledge about household appliances that might cause pollution in the unit Pollution sources investigated were gas stove, cigarette, fragrance, cleaner, and pest spray. Then, understanding on IAQ was the residents' understanding on the anticipation of diseases caused by the lack of tools, materials, and activities to prevent the occurrence of the disease. It consisted of 5 activities: periodical AC checking, seeing a doctor when feeling airborne illness, using chemical finishing material or not, planting pollutant absorbing trees, and avoiding smoking. Potential indoor polluting household appliances were cooking with stove, smoking, using chemical-based deodorizer, cleanser, and pest spray [21]. Participants were given a statement and asked to choose one answer. Data were collected through questionnaires using a Likert scale: strongly agree (5), agree (4), neutral (3), disagree(2), and strongly disagree (1).

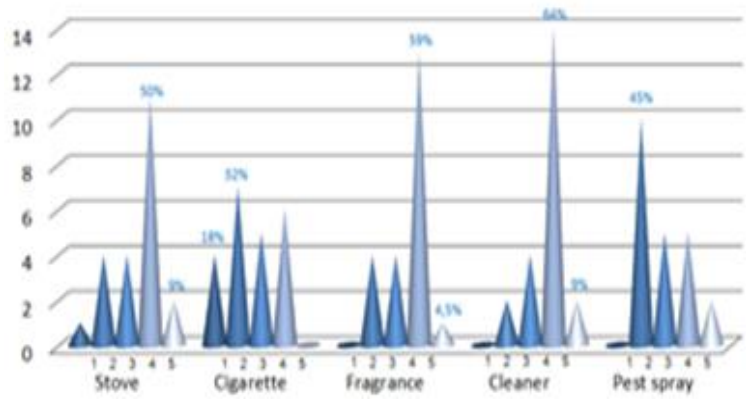

Fig 2. The comparison of participant perception on sources of pollutants.

Figure 2 shows the participant perception of household appliances producing pollutants. More than half or 59\% (50\% agreed and 9\% strongly agreed) of the participants admitted that they did cooking activity with gas stoves, but others did not cook with gas stove or no cooking at all. It means that most of the residents did not always cook every day because they could buy food easily from the restaurants, food court, canteens, and supermarket on the ground floor. So, only some $\mathrm{CO}_{2}$ emitted from cooking. Related to the cigarette, half of the participants (32\% agreed and $18 \%$ strongly agreed) admitted that they still smoked in the unit. They could not leave smoking habit at home eventhough they were aware of its bad effect on their health. Moreover, as shown on figure 2, most participants $(63.5 \%=59 \%$ agreed and 4.5 strongly agreed $)$ said that they did spraying chemical-based fragrance in the unit because they thought the room would be more comfortable with fragrance and they had no thought of harmful chemicals. Further, $73 \%$ of participants stated that they used chemical cleaning fluid to clean dirty surfaces. Almost half of the participants (45\%) refused to place the insect repellent in a place without a cover. Regarding the five sources of indoor pollutant, most of the participants have been careful in using them, but half of the participants admitted still smoking in residential unit. Smoking inside home in urban area of Indonesia is a culture that is still considered full tolerance among educated people [22]. They were less aware of the fact that bringing the habit to high rise building was endangering the health of other residents.

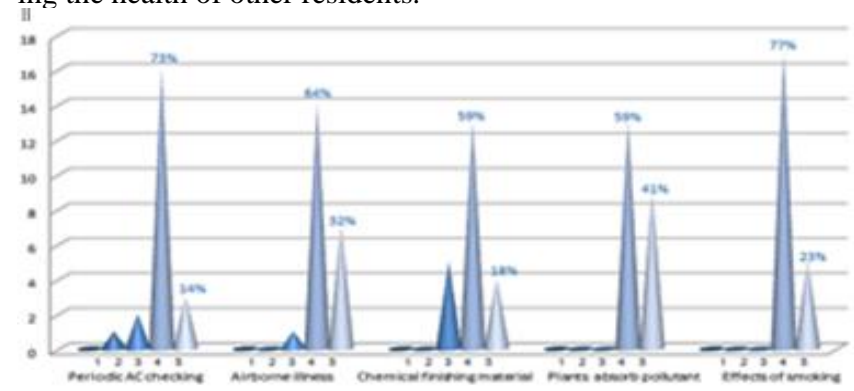

Fig 3. The comparison of participant perception on IAQ understanding
Figure 3 shows the participants' perception on understanding the IAQ. The Sequence from left to right of figure, were the activities that theoretically influenced the IAQ in residential unit: periodical AC checking, avoiding airborne disease, using paint or finishing materials containing hazardous chemicals, multiplying trees to reduce air pollution, and smoking cigarette. First, almost all of the participants $(73 \%$ agreed and $14 \%$ strongly agreed) said that they should check AC periodically. Jakarta is hot and dusty $\left(\mathrm{PM}_{2.5}=61\right)$ $\mathrm{AC}$ is very important in lowering the air temperature as well as filtering dust and germs. Then, almost all of them $(96 \%=64 \%$ agreed and $32 \%$ strongly agreed) mentioned that the disease could be transmitted through indoor air. Furthermore, most of the participants $(59 \%$ agreed $+18 \%$ strongly agreed $=77 \%)$ admitted that finishing materials could emit harmful chemicals. Many participants didn't think that the fragrance in an air-conditioned room could endanger their respiratory health. The theory states that trees can be pollutant absorber, and all of the participans $(59 \%+41 \%=100 \%)$ agreed that plants around the buildings could help to reduce pollutants and they could feel fresh air around the trees. They wanted a lot of trees around the building. All participants agreed that smoking could cause adverse effect on humans and the environment $(77 \%$ agreed $+23 \%$ strongly agreed $=100 \%)$. Related to knowledge of pollutant sources, all participants knew the danger of smoking but the habit was not abandoned yet, beside it was difficult to find smoking room.

The conclusion of this session is that most of the participants have good educational background, so they are generally well-informed to maintain clean and healthy dwelling. On the other hand, if we compare the previous discussion with this section, we can see that participants who has high education do not always conduct activities positively to IAQ since the habit of culture tempted them.

The next discussion is about the influence of residents' occupation on the perception of household appliances that may cause pollutants in the unit. Figure 4 indicates that residents having the health profession were more aware of the source of pollutants than those having the construction profession. Those having construction profession who are aware of the others place the second. Figure 4 reveals the gradation of knowledge on occupation for all polluting house appliances such as gas stove, cigarette, fragrance, cleaner, and pest spray. This means that participants working in the health field have gained a good IAQ knowledge through their education and work. They are the first priority to be involved in improving healthy lifestyle in high rise building. Moreover people with construction background generally have taken health and safety training because their work is often contacted and related to the building materials which contain chemicals. Although their health awareness is not as deep as that of participants with health background but they are more aware of

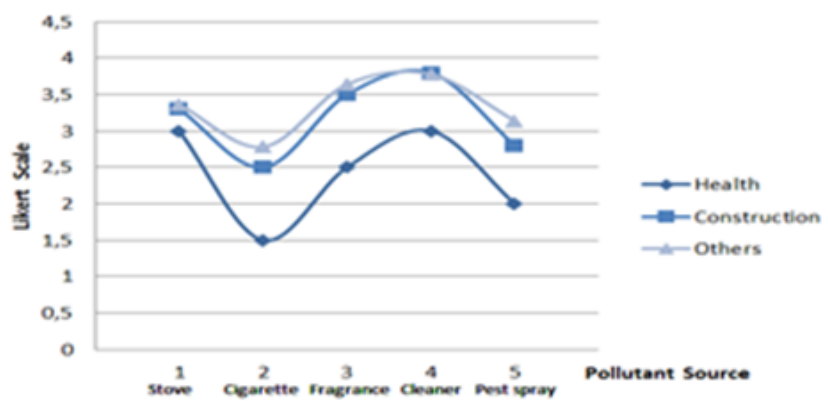

Fig 4. The differences on the knowledge of pollutant sources based on the occupation. 


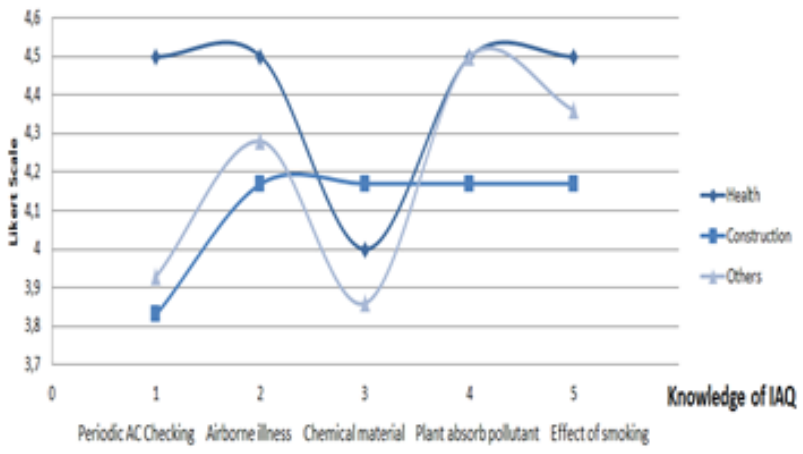

Fig 5. The differences on the knowledge of IAQ based on the occupation

Figure 4 and figure 5 reveal that the participants having health and construction professions are more aware of indoor pollutant sources than those having the other professions and all participants of various professions have a good understanding about IAQ. It is concluded that health professions in this apartment have some potency as a role model and can be involved by the manager in the healthy living program because they understand IAQ and can implement it to their life better than the other professions [19]. This analysis is aimed to see the difference in the strength of the influence among the latent variables of the construct which affects IAQ in resident unit. The latent variables are Residents' dimension as dependent variable, Knowledge of IAQ as moderator variable, and Indoor Air Quality (IAQ) in Unit as independent variable. The analysis was conducted as the constructs shown in figures 6(a) and $6(\mathrm{~b})$

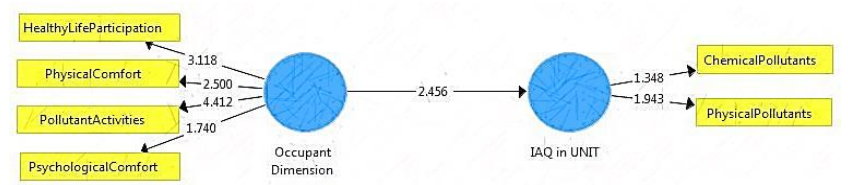

(a)

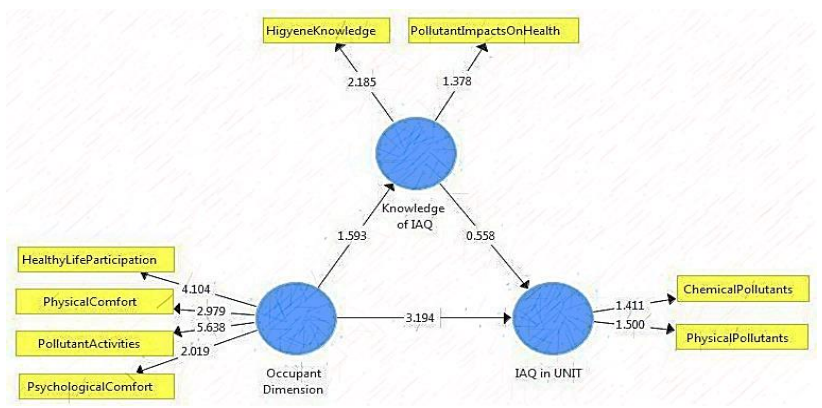

(b)

Fig. 6. Value of PLS without (a) and with (b) knowledge of IAQ

Both figures show the different constructs of Partial Least Square (PLS) among the Residents' dimension, Knowledge of IAQ, and IAQ in Unit. Figure 6(b) shows the complete construct variables: the Resident dimension, Knowledge of IAQ, and IAQ in Unit and figure 6(a) refers to the PLS construct without the Knowledge of IAQ. In PLS, there are two types of relation value, the inner model which shows the relation of the latent variables: Resident dimension, Knowledge of IAQ, and IAQ in Unit and the outer model which shows relation between the latent variable and its indicators. It was found that the difference in values of both constructs shows that figure 6(b) is better than figure 6(a). Figure 6(b) showing the inner model values of the resident dimension to the IAQ in Unit are stronger 2.456 to 3.194 than figure 6(a). The explanation of PLS analysis is divided into two: outer model and inner model. The details of the relation value can be seen in tables as follow (table 1 and table 2).

The statistical assessment in PLS for outer model can be verified by validiting the value of convergence and reliability. It was a good enough validity value above 0.5 , on the basis of this, the converge and reliability meet the requirement. Table 1 shows that the values of convergence and reability of both constructs are not significantly different. For example, the value of the convergence validity of healthy life participation in the first construct is 0.754 closer to the second construct value which is 0.746 . Another example, the value of the reliability validity of Resident dimension in the first construct which is 0.863 is not significantly different from the second construct which is 0.862 . It means the outer models of the both constructs statistically meet the requirement. It indicates that these constructs can be used as the formulation to illustrate a part of the concept of IAQ sustainability in high rise building.

The statistical assessment for inner model in PLS can be verified by $t$-Test and the percentage of influence can be verified by $R$ square. The t- Test meets the requirement if the value is above 1.96. Table 2 indicates that the $\mathrm{T}$ test value of the variable Resident dimension to the variable IAQ in Unit is significantly different between the both constructs. T-test value of the construct with IAQ knowledge for direct effect is 3.420 which is higher than the construct without IAQ knowledge which is 1.995 . Then, from the indirect effect, the T value is permanently higher. Staying in Table 2 for $\mathrm{R}$ square, the influence value of construct with IAQ knowledge is $16.6 \%$ which is higher than the construct without knowledge of IAQ (15.2\%). It means that the IAQ Knowledge fills the rest of influence value from $15.2 \%$ to $16.6 \%$, around $1,4 \%$ of the formulation. Variable of IAQ Knowledge makes the influence of Resident dimension to IAQ in Unit stronger. Besides, there are other variables that influence the IAQ in Unit with the value of $83.4 \%$ of the construct with IAQ Knowledge.

Table 1. Relation Value of Outer Model

\begin{tabular}{|l|l|l|}
\hline Convergence Validity & Loading Factor (>0.5) \\
\hline Resident Dimension & $\begin{array}{l}\text { Without Knowledge Of } \\
\text { Iaq (A) }\end{array}$ & $\begin{array}{l}\text { With Knowledge } \\
\text { Of Iaq (B) }\end{array}$ \\
\hline $\begin{array}{l}\text { Healthy Life Participa- } \\
\text { tion }\end{array}$ & $\mathbf{0 . 7 5 4}$ & $\mathbf{0 . 7 4 6}$ \\
\hline Physical Comfort & 0.822 & 0.839 \\
\hline Pollutant Activities & 0.862 & 0.852 \\
\hline Psychologicalcomfort & 0.684 & 0.681 \\
\hline Knowledge Of Iaq & & 0.847 \\
\hline Health Impact On & - & 0.614 \\
\hline $\begin{array}{l}\text { Pollutant } \\
\text { Health }\end{array}$ & & \\
\hline Iaq In Unit & 0.601 & 0.644 \\
\hline Chemical Pollutants & 0.688 & 0.647 \\
\hline Physical Pollutants & \multicolumn{2}{|l}{} \\
\hline & Composite Reliability (>0.5) \\
\hline Reliability Validity & $\mathbf{0 . 8 6 3}$ & $\mathbf{0 . 8 6 2}$ \\
\hline Resident Dimension & \multicolumn{2}{|l}{0.702} \\
\hline Knowledge Of Iaq & 0.588 & 0.588 \\
\hline Iaq In Unit &
\end{tabular}

Table 2. Relation Value Of Inner Model

\begin{tabular}{|l|l|l|}
\hline T-TEST & T STATISTICS (>1.96) \\
\hline Direct Effect & $\begin{array}{l}\text { Without Knowledge } \\
\text { of IAQ (a) }\end{array}$ & $\begin{array}{l}\text { With Knowledge of } \\
\text { IAQ (b) }\end{array}$ \\
\hline $\begin{array}{l}\text { Resident dimension > } \\
\text { IAQ in UNIT }\end{array}$ & $\mathbf{1 . 9 9 5}$ & $\mathbf{3 . 4 2 0}$ \\
\hline $\begin{array}{l}\text { Knowledge of IAQ > } \\
\text { IAQ in UNIT }\end{array}$ & 0.542 \\
\hline $\begin{array}{l}\text { Resident Dimension } \\
>\text { Knowledge of IAQ }\end{array}$ & & 1.655 \\
\hline Indirect Effect & & $1.655+0.542=2.197$ \\
\hline $\begin{array}{l}\text { Resident dimension > } \\
\text { IAQ in UNIT }\end{array}$ & & \\
\hline \multicolumn{2}{|l|}{} & $\mathbf{1 6 . 6 \%}$ \\
\hline $\begin{array}{l}\text { PERCENTAGE OF } \\
\text { INFLUENCE }\end{array}$ & R SQUARE & $10.3 \%$ \\
\hline $\begin{array}{l}\text { Resident dimension } \\
>\text { IAQ in UNIT }\end{array}$ & $\mathbf{1 5 . 2} \%$ & \\
\hline $\begin{array}{l}\text { Resident dimension } \\
>\text { Knowledge of IAQ }\end{array}$ & & \\
\hline
\end{tabular}


The result of this study indicates that the residents' IAQ Knowledge in high rise building can make the influence between resident dimension to IAQ in unit stronger. This indicates that the residents' knowledge can improve IAQ sustainability. There are other more variables besides residents' dimension and knowledge that affect IAQ sustainability. Spengler has stated that all of the integrated encouragement for sustainable IAQ is called socially responsible investment for designing a healthy living in the high rise building [23]

\section{Conclusions}

The findings of this research have shown that there is a need for integrated programs for rusunami that are driven by Jakarta Provincial Government by creating a few policies on behavior guidance in high-rise residential buildings, which lead to community empowerment for healthy living style. The policies that guide planners and company owners to complete a thorough design program up to several years of functioning and evaluating buildings with which IAQ measurements must be designed. The communities who are going to live in the high rise buildings should be in cluded in the preparatory program at the beginning of the adjustment period. The building manager will benefit if the residents trust the sustainability of their lives in the building. GBCI (Green Building Council Indonesia) has stated that the socialization can be in form of posters such as warning of the hazard pollution or role-model programs of healthy living.

This research is more directed to the social aspects of the concept of the environment. It has not yet studied further on the economic and environmental aspects. The continuation of this research will focus on those two aspects. In addition, the further research will consider the evaluation of the role of local government's representation in managing healthy living of the rusunami apartment in Jakarta related to IAQ sustainability.

\section{Acknowledgment}

As a token of appreciation, the authors would like to express high appreciation to Jakarta Provincial Government and Scholarship Foundation in Jakarta who helped the writers complete the research.

\section{References}

[1] M. S. Silva, S. Maas, H. A. De Souza, A. P. Gomes, "Post Occupancy Evaluation of Residential Buildings in Luxemburg," Energy and Building, 148,119-127, 2017.

[2] J. K. Day, D. E. Gunderson, "Understanding High Performance buildings," J. of Building and Env.2015.

[3] S. E. Jones, A. M. Smith, L. S. Wheeler, T. Mc Manus, "Scholl Policies and Practices," J. of School Health, 80, 6, 2010.

[4] W. P. Alford, R. P. Weller, L. Hall, K. R. Polenske, Y. Shen, D. Zweig, "Human Dimension, " J. of Contemporary China, 32, 2002.

[5] Y. Jin, X. Ma, X. Chen, Y. Cheng, E. Baris, M. Ezzati, "Exposure to IAP from Household Energy use in Rural China," Social Sci.\& Medicine 62, 3161-3176, 2006.

[6] R. Gifford, "The Consequences of Living in High-Rise Building,” J. Architectural Sci. Rev., 50, 1, 2007. H. Maslow, Start Publishing LLC, 979-1-62793-396-4, 2012.

[7] S. A. McLeod, Simplypsychology.org, 2017.

[8] G. T. Miller, S. E. Spoolman, Brooks/Cole, 2012

[9] WHO, Mortality and Burden of disease Attributetable to selected major risks, 9789241563871, 2009.

[10] M. Ezzati, D. M. Kammen, "Household Energy, IAP and Health in Dev. Countries," Annual Rev Energy Env., 27, 233270, 2002.

[11] R. Puwarna, "PM10 as Predictor of Ventilation Efficiency of Houses in Relation to Health," Medical J.of Indonesia, 14, 4 237-241, 2005
[12] W. Gautami, E. Syahruddin, E-J. Kedokteran Indonesia 23386037, 1, 3, 202-207, 2013.

[13] K. W. Tham, "IAQ and Its Effects on Human," J.of Energy Building, 130, 637-650, 2016.

[14] B. R. Barnes, "Behavioral Change, IAP and Child Respiratory," International J.of Env. Research and Public Health 16604601, 2014.

[15] V. Loftness, B. Hakkinen, O. Adan, A. Nevalainen, J. Env.Health Perspectives, 2007.

[16] J. Hawkes, Culture â€TM s Essential Role In Public Planning, 2017.

[17] H. Madanat, M. D. Barnes, "Knowledge of The Effects of IAQ on Health among Women," Health Education \& Behavior, 35, 105-118, 2008.A. Wilcock, "Bridging Occupation and Health," Canadian J. of Occupational Therapy, 72, 10, 5-12, 2004.

[18] H. Ojha, M. Pramanick, "Effect of Age on Intensity and Priority of Life Needs," J. of The Indian Academy of Applied Psycho., 35, 1, 131-136, 2009

[19] WHO, Environmental Health, 2016.

[20] F. K. Rahim, T. Suksaroj, I. Jayasvasti, " Social Determinant of Health of Adult Smoking Behavior," National Public Health J, 11, 2, 51-55, 2016.

[21] J. D. Spengler, Q. Chen, "IAQ Factors in Designing A Healthy Building," J.of Annual Rev. Of Energy And The Env., 25, 567$600,2000$.

[22] Republik Indonesia. (2012). Keputusan Presiden Nomor 70 Tahun 2012 - Pengadaan Barang/Jasa Pemerintah. Jakarta: Republik Indonesia.

[23] Teo, T. S., Lin, S., \& Lai, K.-h. (2009). Adopters and nonadopters of e-procurement in Singapore: An empirical study. Omega, 37, 972-987.

[24] Yap Kioe Sheng (2005). What is Good Governance? Poverty Reduction Section. United Nations Economic and Social Commission for Asia and the Pacific. 